\title{
Tactile pattern recognition by graphic display: Importance of 3-D information for haptic perception of familiar objects
}

\author{
YUTAKA SHIMIZU \\ Tsukuba College of Technology, Tsukuba, Ibaraki, Japan \\ SHINYA SAIDA \\ Industrial Products Research Institute, Tsukuba, Ibaraki, Japan \\ and \\ HIROSHI SHIMURA \\ National Institute of Special Education, Yokosuka, Kanagawa, Japan
}

\begin{abstract}
Haptic recognition of familiar objects by the early blind, the late blind, and the sighted was investigated with two-dimensional (2-D) and three-dimensional (3-D) stimuli produced by small tactor-pins. The 2-D stimulus was an outline of an object that was depicted by raising tactor-pins to $1.5 \mathrm{~mm}$. The 3-D stimulus was a relief that was produced by raising the tactors up to $10 \mathrm{~mm}$, corresponding to the height of the object. Mean recognition times for correct answers to the 3-D stimuli were faster than those for the 2-D stimuli, in all three subject groups. No statistically significant differences in percentage of correct responses between the 2-D and the 3-D stimuli were found for the late-blind and sighted groups, but the early-blind group demonstrated a significant difference. In addition, the haptic legibility for the quality of depiction of the object, without regard to whether or not the stimulus was understood, was measured. The haptic legibility of the 3-D stimuli was significantly higher than that of the 2-D stimuli for all the groups. These results suggest that $3-\mathrm{D}$ presentation seems to promise a way to overcome the limitations of 2-D graphic display.
\end{abstract}

As a result of recent advances in computer technology, it has become possible to translate written text into synthesized speech for the blind. However, pattern information that contains multidimensional characteristics such as shape, size, and texture is difficult to transmit by the synthesized speech. Therefore, tactile reception of pattern information is still important for the blind. This study concerns tactile pattern recognition in a graphic display system that is being developed at our laboratory.

At present, two types of transitory tactile displays have been devised. One is a matrix of vibrators that are selectively activated to form a pattern (e.g., Bliss, Katcher, Rogers, \& Shepard, 1970; Collins, 1970). The other is a matrix of tactor-pins that produces raised-dot drawings or solid forms (e.g., Friksen-Gibson, Bach-y-Rita, Tompkins, \& Webster, 1987; Shimizu, 1986). In order to use the former type, subjects generally have to fix their skin against the display to perceive the object being presented. The latter type, on the contrary, essentially depends on active touch (Gibson, 1962). Both types of display have been used in many psychological studies (e.g., Heller \& Schiff, 1991).

This research was supported by the Agency of Industrial Science and Technology, MITI-Japan (the three-dimensional display for the blind). Address correspondence to $Y$. Shimizu, Tsukuba College of Technology, 4-3-15, Amakubo, Tsukuba, Ibaraki 305, Japan.
Optacon (e.g., Bliss et al., 1970), a vibrotactile reading machine that presents patterns passively, is useful for alphanumeric letter identification. Furthermore, many applications that have been used transmit pattern information by vibrotactile display (e.g., Sherrick, 1991; Shimizu, Saida, Wake, Nakamura, \& Ohzu, 1982). However, it seems difficult to transmit complicated patterns because of the limited reception of information that can be presented by this type of display. Because both cutaneous and kinesthetic information have been found to be important in the tactile perceptual system (e.g., Gibson, 1962; Loomis \& Lederman, 1986), haptic search is one of the most important factors for tactile recognition. Therefore, the graphic display system that we are now developing depends upon active haptic exploration.

Much research has been performed to obtain knowledge about tangible graphics that use active haptic exploration (e.g., Barth, 1984; Lambert \& Lederman, 1989; Lederman \& Campbell, 1982). In these experiments, raised points or lines produced on a paper or a plastic film were used for tactile stimuli. From these graphics, information about the texture and temperature of real objects was absent, and the representation of size and shape was restricted. Thus, pattern identification using tangible graphics is less effective in some cases (e.g., Lederman, Klatzky, Chataway, \& Summers, 1990). However, these 
stimuli are not three-dimensional (3-D), but are twodimensional (2-D) patterns, because they provide no information about the height or depth of the object.

Experiments using 3-D stimuli are not as frequently performed as are those using 2-D stimuli. Garbin and Bernstein (1984) pointed out that the key factors influencing 3-D tactile recognition might be at the level of composites of patterns such as size and shape, rather than at the level of characteristics of patterns such as symmetry, as long as the stimuli are meaningless solid forms. Pattern identification of very familiar objects by haptic recognition, however, was found to be excellent by Klatzky, Lederman, and Metzger (1985). They pointed out that the reason for this excellent recognition might be that the real objects contained composites such as texture, size, shape, temperature, and weight. These composites effectively operate for integrative identification of objects.

In any case, 3-D presentation may excel over 2-D presentation because of its ability to provide information about height or depth. The tactile graphic display that we have developed provides a technological possibility for the production of 3-D patterns because each tactor-pin can be raised to multilevel height or deptin. The main objective of the present study was to compare 3-D recognition of familiar objects with 2-D recognition by using the tactile graphic display. In addition, we assessed the validity of the 3-D graphic display, that is, whether 3-D recognition overcomes the limitation of 2-D recognition. Finally, because it has been pointed out that there are differences in haptic recognition between the blind and the sighted (e.g., Heller, 1989; Kennedy \& Fox, 1977), we used both blind and sighted subjects.

\section{METHOD}

\section{Apparatus}

The structure of the graphic display used in this experiment is illustrated in Figure 1. Each tactor-pin was freely movable up to $30 \mathrm{~mm}$ in height by a stage that was adjustable. Models of familiar objects were manufactured: For 2-D models, wire was bent to form the outine of the objects and for 3-D models, similarly sized clay reliefs that contained height information were manufactured. In order to produce a stimulus pattern, one of these models was mounted upon the adjustable stage, beneath the tactor-pins.

Two arrangements of the display were devised. One consisted of 1,827 tactor-pins arranged with 3-mm interspacing. The other consisted of 3,927 pins with $2-\mathrm{mm}$ interspacing. The density of the $2-\mathrm{mm}$ display corresponded to about 0.8 times the two-point discrimination threshold, and the 3-mm display corresponded to about 1.2 times the two-point discrimination threshold at the fingertip (see Weinstein, 1968). In order to produce a smooth depiction, the pins were not arranged in a square formation, but in a hexagonal formation instead, relative to one another within a $120 \times 120 \mathrm{~mm}$ frame in both displays. Each tactor-pin, which was made of resin, was curved at the top. The diameter of the tactor-pin was $2.75 \mathrm{~mm}$ for the $3-\mathrm{mm}$ arrangement, and $1.75 \mathrm{~mm}$ for the $2-\mathrm{mm}$ arrangement.

\section{Stimuli}

Ten familiar objects were selected as stimuli. The objects, their presentation orientations, and the scale to which their sizes were altered are shown in Table 1. For the 2-D stimuli, the height of all the tactor-pins was adjusted to $1.5 \mathrm{~mm}$ by a vernier on the adjustable stage. For the $3-\mathrm{D}$ stimuli, the tactor-pins were movable to any height up to $10 \mathrm{~mm}$, according to the shape of the object. Examples of stimuli are shown in Figure 2. Figure 2a represents the palm displayed in the $2-\mathrm{D}$ condition and Figure $2 \mathrm{~b}$ represents that of the 3-D condition.

\section{Procedure}

Prior to the stimuli presentation, the subjects were told that the stimuli to be presented were all familiar objects such as plants, animals, body parts, or household items, although the sizes would usually be smaller than in reality. They were also told that the orientations that would be depicted would not always be the same. The subjects were then asked to respond by naming the object as quickly and accurately as possible. No feedback was given for correct answers at each presentation. There was no limit on haptic exploration to identify the stimulus, and the maximum exploration time was unlimited for each trial.

The subjects' reaction (or recognition) times (RTs) and responses were recorded. After a response, haptic legibility was measured. This was a rating made by the subject as to whether the stimulus was a good or bad depiction of the object, regardless of whether or not the stimulus had been correctly identified. The subject assigned a number to each stimulus from -3 (worst) to +3 (excellent); 0 was neutral (neither). Each subject responded to 20 stimuli (10 patterns $\times 2$ displays) presented in random order.

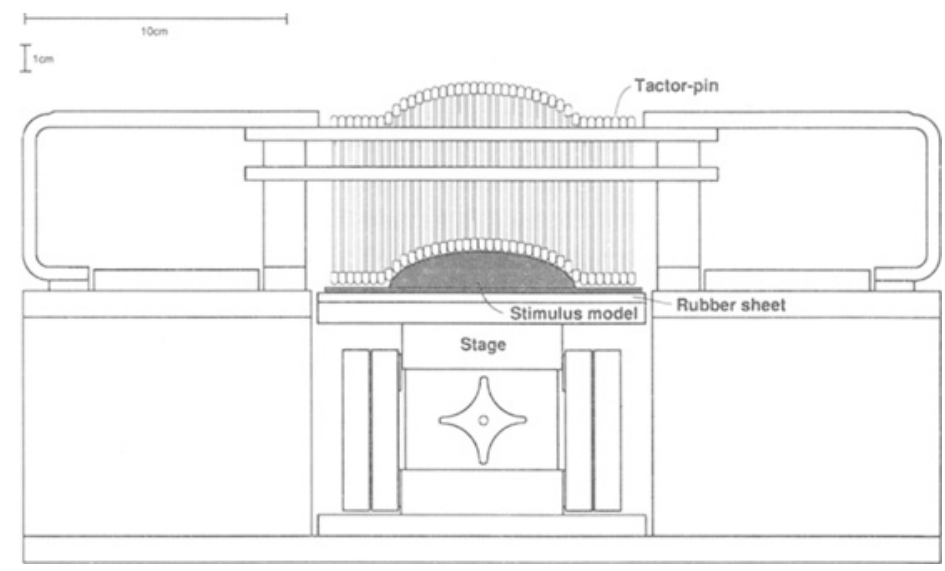

Figure 1. Structure of tactile graphic display used in the experiment. 
Table 1

Objects, Presentation Orientations, and Sizes to Which the Objects Were Altered

\begin{tabular}{llc}
\hline Objects & Orientations & Sizes* \\
\hline Bottle & Side & 0.5 \\
Face & Front (male) & 0.5 \\
Apple & Side & 1.0 \\
Hand & Palm (left) & 0.7 \\
Fish & Side & 0.8 \\
Cherry & Side & 1.1 \\
Scissors & Top & 1.0 \\
Fork & Top & 1.0 \\
Kettle & Side & 0.4 \\
Plug & Top & 1.1
\end{tabular}

*Means ratio compared with the real object.

\section{Subjects}

Three groups of subjects participated in the experiment. The first group consisted of 6 male and 3 female late-blind people with a mean age of 40.2 years $(S D=10.6)$. The mean age of the onset of blindness was 22.4 years $(S D=7.8)$. The second group consisted of 3 male and 6 female early-blind people, with a mean age of 27.7 years $(S D=12.5)$. The third group consisted of 5 male and 5 female sighted subjects, with a mean age of 24.5 years $(S D=$ 8.5). The sighted subjects were blindfolded during the experiment. The blind subjects were students or staff of blind schools, and the sighted subjects were students or staff of a research institute.

\section{RESULTS}

No significant difference in percentage of correct responses between the $2-\mathrm{mm}$ and $3-\mathrm{mm}$ arrangements was found by the paired $t$ test $[t(8)=.80$ for the late-blind group, $t(8)=.76$ for the early-blind group, and $t(9)=$ 1.96 for the sighted group in the 2-D display; and $t(8)=$ 1.79 for the late-blind group, $t(8)=1.51$ for the earlyblind group, and $t(9)=1.00$ for the sighted group in the 3-D display]. Similarly, no significant difference in RTs of correct responses between the 2-mm and $3-\mathrm{mm}$ arrangements was found $[t(156)=.22$ for the late-blind group, $t(111)=1.40$ for the early-blind group, and $t(189)=.53$ for the sighted group in the 2-D display; and $t(158)=.21$ for the late-blind group, $t(126)=.10$ for the early-blind group, and $t(194)=.39$ for the sighted group in the 3-D display]. Therefore, correct responses for both the 2-mm and 3-mm arrangements were cumulated for further analyses.

\section{Comparison Between the 2-D and 3-D \\ Presentations in Percentage of Correct Responses}

Table 2 shows the percentage of correct responses for each group. The percentage of correct responses for the 3-D stimuli was greater than that for the 2-D stimuli in all the groups. Highly significant differences, indicating that the 3-D stimuli were identified better than the 2-D stimuli, were found in the early-blind group. However, no significant difference was indicated for the late-blind and sighted groups.

\section{Comparison Between the 2-D and 3-D Presentations in Recognition Times}

Distributions of correct RTs are shown in Figures 3a and $3 \mathrm{~b}$, which show the results of the 2-D and 3-D presentations, respectively. Horizontal axes represent RTs scaled in log seconds, and vertical axes represent percentage frequencies of correct answers. The interval width is $5 \mathrm{sec}$ in this frequency distribution. The maximum frequency for the 2-D presentation appears at $7.5 \mathrm{sec}$ for all the subjects, and appears at $2.5 \mathrm{sec}$ for the $3-\mathrm{D}$ presentation. Thus, it is clearly indicated that the subjects responded faster to the 3-D stimuli than to the 2-D stimuli.

\section{Haptic Legibility}

For most of the conditions, except the 3-D presentation in the early-blind group, the evaluated mean scores of the $2-\mathrm{mm}$ arrangement were significantly higher than
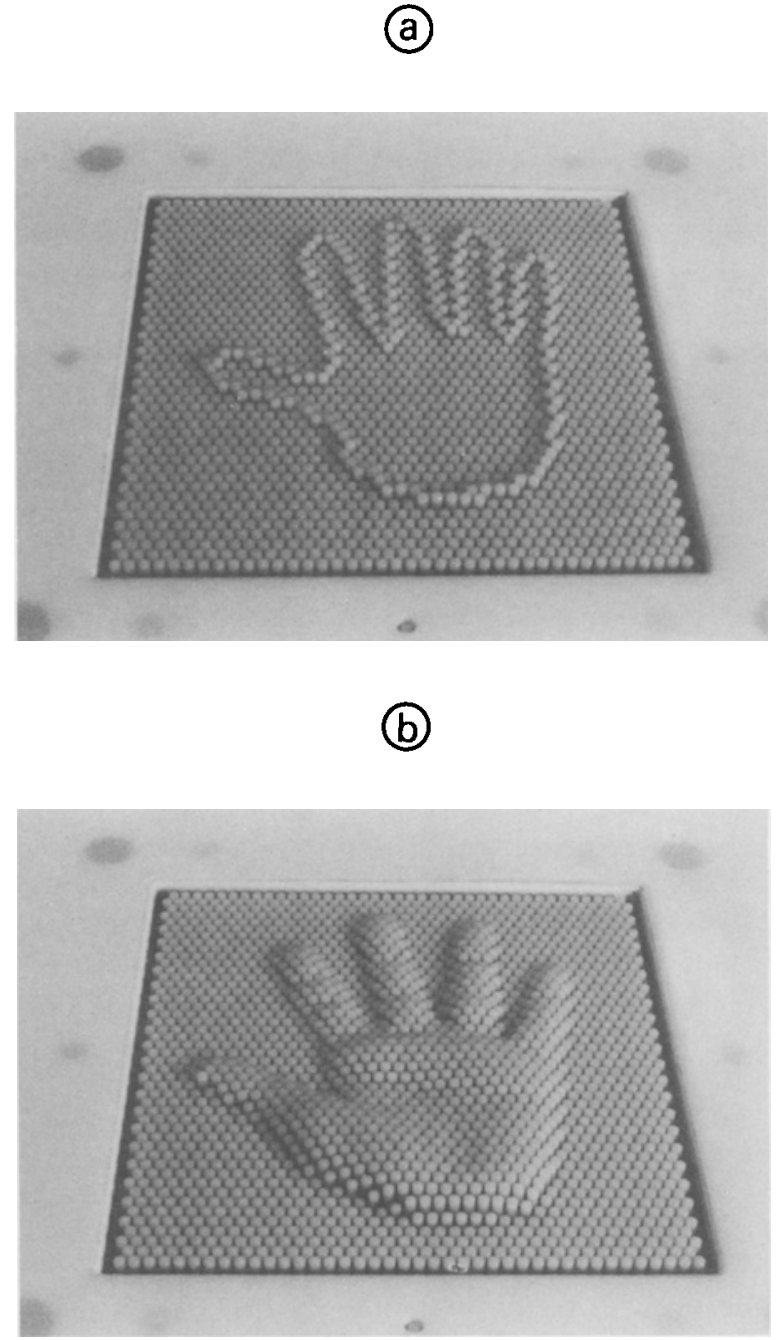

Figure 2. Examples of stimuli produced in the tactile display: The 2-D presentation of the palm (a), and the 3-D presentation (b). 
Table 2

Comparison Between the 2-D and 3-D Presentations in Percentage of Correct Responses for Each Group

\begin{tabular}{lccccc}
\hline Subjects & 2-D & 3-D & $t$ & $d f$ & $p$ \\
\hline Late blind & $87.8 \%$ & $88.3 \%$ & 0.24 & 8 & - \\
Early blind & $61.7 \%$ & $71.1 \%$ & 7.25 & 8 & $<.01$ \\
Sighted & $95.5 \%$ & $98.0 \%$ & 1.63 & 9 & - \\
\hline
\end{tabular}

those of the 3 -mm arrangement $[t(8)=4.06, p<.01$ for the late-blind group, $t(8)=1.46, p<.02$ for the early-blind group, and $t(9)=4.58, p<.01$ for the sighted group in the 2-D presentation; and $t(8)=2.92$, $p<.02$ for the late-blind group, $t(8)=3.44, p<.09$ for the early-blind group, and $t(9)=4.52, p<.01$ for the sighted group in the 3-D presentation]. Therefore, haptic legibility was affected by the density of the examined pin array. Thus, the comparison between the 2-D and 3-D presentations was performed for the 2-mm and 3-mm displays, respectively.

Table 3 shows the results of a comparison between the 2-D and 3-D presentations. It is shown that the 3-D presentations were evaluated significantly better than were the 2-D presentations for all the groups.

\section{Comparison Between the Groups}

Table 4 shows the results of a comparison between the groups by the $t$ test. The percentage of correct responses for the early-blind group was significantly lower than those of the late-blind group ( $p<.01$ in the 2-D presentation; $p<.05$ in the 3-D presentation) and the sighted group $(p<.01$ in the 2-D presentation; $p<.01$ in the 3 -D presentation). There was, however, no significant difference between the sighted and the late-blind groups in the 2-D and 3-D presentations. For mean RTs, there was no significant difference between the groups in the 2-D and 3-D presentations.

Table 5 shows the results of a comparison between the groups in haptic legibility. No significant difference was found, except for the conditions between the late-blind and sighted groups in the 2-mm arrangement $(p<.01$ in the $2-\mathrm{D}$ presentation; $p<.04$ in the 3-D presentation). Differences were found in both the 2-D and 3-D presentations between the late-blind and sighted groups in the 2-mm display, but the reason is still unknown.

\section{DISCUSSION}

There are several methods that increase the amount of information in a 2-D tactile display. One method is to depict details such as shadows, wrinkles, and hollows of an object by lines or dots. However, providing such information will not improve 2-D recognition, because of the limitations of tactile resolution. Another method is to project the object from 3-D to 2-D in the 2-D plane. However, it has been found that early-blind subjects have difficulty in imaging original objects from their 2-D depictions (Wake, Shimizu, \& Wake, 1980). It has also been found that the early blind perform almost the same for
2-D and 3-D depictions, in the recognition of 2-D patterns (Lederman et al., 1990). Therefore, these methods, which are supposed to increase the amount of information, do not seem to improve haptic recognition.

On the contrary, the 3-D presentation used in this experiment, which depicts the spatial proportion of the entity by adding height information, seemed to be one of the superior methods. The RTs for the 3-D presentation were faster than those for the 2-D presentation for all the groups (see Figures 3a and 3b), and, furthermore, the evaluated scores of haptic legibility of the 3-D presentation were superior to those of the 2-D presentation (see Table 3).

The addition of the third dimension showed the increase in the amount of information transmitted by the informa-
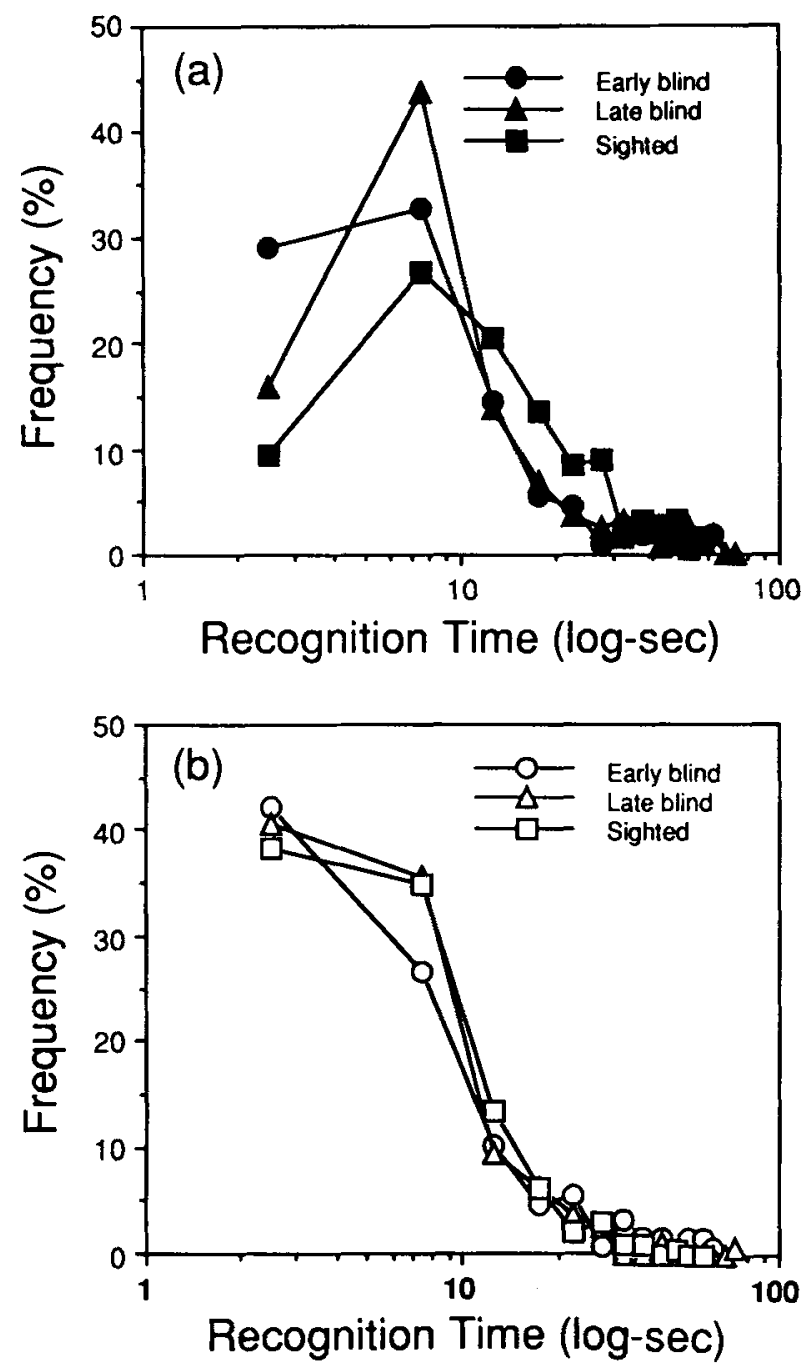

Figure 3. Frequency distribution for recognition time in $5 \sec$ of interval width. Vertical axes represent percentage frequency of correct responses, and horizontal axes represent recognition time scaled in $\log$ seconds. Shown are results of the $2-D$ presentation (a), and the 3-D presentation (b). 
Table 3

Comparison Between the 2-D and 3-D Presentations in Haptic Legibility

\begin{tabular}{ccrcccc} 
& & \multicolumn{2}{c}{ Mean Rating } & & & \\
\cline { 2 - 6 } Subjects & Arrangement & 2-D & $3-\mathrm{D}$ & $t$ & $d f$ & $p$ \\
\hline Late blind & $2 \mathrm{~mm}$ & 0.44 & 2.16 & 5.41 & 8 & $<.001$ \\
& $3 \mathrm{~mm}$ & -0.09 & 1.64 & 5.19 & 8 & $<.001$ \\
Early blind & $2 \mathrm{~mm}$ & 1.29 & 2.07 & 2.49 & 8 & $<.038$ \\
& $3 \mathrm{~mm}$ & 0.98 & 1.63 & 3.35 & 8 & $<.012$ \\
Sighted & $2 \mathrm{~mm}$ & 1.41 & 2.58 & 6.34 & 9 & $<.001$ \\
& $3 \mathrm{~mm}$ & 0.28 & 1.91 & 6.19 & 9 & $<.001$ \\
\hline
\end{tabular}

tion analysis (Attneave, 1959). The amount of transmitted information was increased by 0.42 bits in the early-blind group (2.14 bits for the 2-D stimuli and 2.56 bits for the 3-D stimuli), by 0.10 bits in the late-blind group ( 2.88 bits for the 2-D stimuli and 2.98 bits for the 3-D stimuli), and by 0.09 bits in the sighted group (3.19 bits for the 2-D stimuli and 3.28 bits for the 3-D stimuli). Thus, the effect of the addition of the third dimension appeared most prominently in the early-blind group.

For the mean percentage of correct responses, however, no significant difference between the 2-D and 3-D presentations was found for the late-blind and sighted groups (Table 2). Several factors might explain this insignificance. One is a ceiling effect of recognition, because percentage of correct responses for the late-blind and the sighted groups ranged from $65 \%$ to $100 \%$. The second factor is the sample size. Only 10 objects were presented in both the 2-mm and 3-mm arrangements, so familiarity could have reduced the uncertainty, although correct answers were not announced for each presentation. The third one is the existence of visual experience in the late-blind subjects, which will be discussed later.

The percentage of correct responses in the late-blind group was greater than that for the early-blind group in both 2-D and 3-D presentations. This tendency is in accordance with the results of previous studies that were performed with 2-D stimuli (e.g., Heller, 1989). There are several theoretical explanations that may clarify the inferiority of pattern recognition in the early blind, such as deprivation of visual experience (see Warren, 1984); skill of haptic exploration (Magi \& Kennedy, 1980); characteristics of egocentric coding (Miller, 1981); or problems with making decisions (Heller, 1989). The imaging model is also proposed to explain the difference between visual and tactile recognition (Klatzky \& Lederman, 1987). Further experimentation is needed to explore these explanations, because our present objective was not to examine the perceptual mechanisms of the blind.

In our present experiment, however, three remarkable distinctions should be noted. One is the differences in the strategies of tactual exploration. Although the subjects were not instructed as to the method of haptic exploration, we observed peculiar movements by some of the early-blind subjects. While most of the subjects moved their fingertips and palms widely and smoothly, some of

Table 4

Comparison Between Groups in Percentage of

Correct Responses and Mean Recognition Times

\begin{tabular}{|c|c|c|c|}
\hline & & Early Blind & Sighted \\
\hline \multicolumn{4}{|c|}{ 2-D Presentation } \\
\hline $\begin{array}{l}\text { Late blind } \\
\text { Early blind }\end{array}$ & $\begin{array}{l}\% \text { Correct } \\
\text { Mean RT } \\
\% \text { Correct } \\
\text { Mean RT }\end{array}$ & $\begin{array}{l}t(16)=3.11, p<.01 \\
t(16)=0.35, p<.73\end{array}$ & $\begin{array}{l}t(17)=1.56, p<.14 \\
t(17)=1.11, p<.28 \\
t(17)=4.67, p<.01 \\
t(17)=0.32, p<.75\end{array}$ \\
\hline \multicolumn{4}{|c|}{ 3-D Presentation } \\
\hline $\begin{array}{l}\text { Late blind } \\
\text { Early blind }\end{array}$ & $\begin{array}{l}\text { \% Correct } \\
\text { Mean RT } \\
\% \text { Correct } \\
\text { Mean RT }\end{array}$ & $\begin{array}{l}t(16)=2.06, p<.05 \\
t(16)=0.07, p<.94\end{array}$ & $\begin{array}{l}t(17)=1.98, p<.06 \\
t(17)=0.26, p<.80 \\
t(17)=1.98, p<.01 \\
t(17)=1.24, p<.23\end{array}$ \\
\hline
\end{tabular}

Table 5

Comparison Between Groups in Haptic Legibility

\begin{tabular}{lccc}
\hline & Arrangement & Early Blind & Sighted \\
\hline \multirow{4}{*}{ Late blind } & $2 \mathrm{~mm}$ & $t(16)=1.81, p<.09$ & $t(17)=2.84, p<.01$ \\
Early blind & $3 \mathrm{~mm}$ & $t(16)=1.98, p<.06$ & $t(17)=0.92, p<.37$ \\
& $2 \mathrm{~mm}$ & & $t(17)=0.33, p<.75$ \\
& $3 \mathrm{~mm}$ & & $t(17)=1.63, p<.12$ \\
& & $3-D$ Presentation & \\
Late blind & $2 \mathrm{~mm}$ & $t(16)=0.30, p<.77$ & $t(17)=2.17, p<.04$ \\
& $3 \mathrm{~mm}$ & $t(16)=0.32, p<.97$ & $t(17)=0.87, p<.39$ \\
Early blind & $2 \mathrm{~mm}$ & & $t(17)=1.94, p<.07$ \\
& $3 \mathrm{~mm}$ & & $t(17)=0.96, p<.35$ \\
\hline
\end{tabular}


the congenitally blind subjects did not. For example, some of the subjects left their fingertips for a long time at a few selected places, such as an edge or endpoint of the object, or pinched only some raised portion, whereas the late-blind and sighted groups mostly moved their fingers or palms smoothly.

The second distinction is the difference in the mean age of the subject groups. The mean age of the late-blind group was 45 years, whereas the mean age of the early-blind group was 21 years. Thus, a longer history of tactual experience may have given the late-blind group an advantage in pattern recognition, in addition to having had previous visual experience. The mean age of onset of blindness for the late-blind subjects was 22.7 years. They had had previous visual experience and most of them had received an education in geometric notation through visual media at school. Thus, they had had enough opportunities to compare objects and their visual drafts, especially the 2-D outlines of those forms. Therefore, it is suggested that the association of 3-D forms and 2-D outlines of those forms, in this experiment, was as feasible for them as it was for the sighted subjects. However, the early-blind subjects had no opportunities to make such comparisons visually. Furthermore, they were provided with very few opportunities to make those comparisons by haptic observation. These differences in visual experiences may have affected the results.

The third distinction is that the overall percentage of correct responses was much greater than had been found previously (e.g., Kennedy \& Fox, 1977; Lederman et al., 1990; Magi \& Kennedy, 1980), although the percentage of correct responses for the early-blind was inferior to that of the late-blind and sighted groups (Table 4). The reason for the high performance in the present results has been discussed previously.

In any case, we confirmed that a 3-D graphic display shows promise as a communication aid for the blind, although it does not present information such as texture, temperature, size, and weight, which may be necessary for identifying an object. Although further experiments are necessary to obtain information about the recognition of meaningless patterns, the 3-D presentation seems to be a useful method of displaying graphics information because it provides information about depth dimension, which can depict the spatial proportion of an entity.

\section{REFERENCES}

ATtNeave, F. (1959). Applications of information theory to psychology. New York: Holt, Rinehart \& Winston.

BARTH, J. L. (1984). Incised grids: Enhancing the readability of tangible graphs for the blind. Human Factors, 26, 61-70.

Bliss, J. C., Katcher, M. H., Rogers, C. H., \&hepard, R. P. (1970). Optical-to-tactile image conversion for the blind. IEEE Transactions on Man-Machine Systems, MMS-1, 58-65.
Collins, C. C. (1970). Tactile television: Mechanical and electrical image projection. IEEE Transactions on Man-Machine Systems, MMS-1, 65-71.

FrIKSEN-Gibson, S. F., BACH-Y-Rita, P., TOMPKINS, W. J., \& WeBSTER, J. G. (1987). A 64-solenoid four-level fingertip search display for the blind. IEEE Transactions on Biomedical Engineering, BME-34, 963-965.

Garbin, C. P., \& Bernstein, I.H. (1984). Visual and haptic perception of three-dimensional solid forms. Perception \& Psychophysics, 36, 104-110.

Gibson, J. J. (1962). Observations on active touch. Psychological Review, 69, 477-491.

Heller, M. A. (1989). Picture and pattern perception in the sighted and the blind: The advantage of the late blind. Perception, 18, 379-389.

Heller, M. A, \& SCHIFF, W. (1991). The psychology of touch. Hillsdale, NJ: Erlbaum.

Kennedy, J. M., \& Fox, N. (1977). Pictures to see and pictures to touch. In D. Perkins \& B. Leonder (Eds.), The arts and cognition (pp. 118-135). Baltimore, MD: Johns Hopkins University Press.

KLATZKY, R. L., \& LeDERMAN, S. J. (1987). The intelligent hand. In G. Bower (Ed.), The psychology of leaming and motivation (Vol. 21 , pp. 121-151). San Diego: Academic Press.

Klatzky, R. L., Lederman, S. J., \& Metzger, V. A. (1985). Identifying objects by touch: An "expert system." Perception \& Psychophysics, 37, 299-302.

LamberT, L., \& Lederman, S. J. (1989). An evaluation of the legibility and meaningfulness of potential map symbols. Joumal of Visual Impairments \& Blindness, 83, 397-403.

Lederman, S. J., \& Campbell, J. I. (1982). Tangible graphs for the blind. Human Factors, 24, 85-100.

Lederman, S. J., Klatzky, R. L., Chataway, C., \& Summers, C. D. (1990). Visual mediation and the haptic recognition of twodimensional pictures of common objects. Perception \& Psychophysics, 47, 54-64.

Loomis, J. C., \& Lederman, S. J. (1986). Tactual perception. In K. Boff, L. Kaufman, \& J. Thomas (Eds.), Handbook of human perception and performance (pp. 1-41). New York: Wiley.

MAGI, L. E., \& KenNEDY, J. M. (1980). Exploring pictures tactually. Nature, 283, 287-288.

MILLER, S. (1981). Self-referent and movement cues in coding spatial location by blind and sighted children. Perception, 10, 255-264.

SHERRICK, C. (1991). Vibrotactile pattern perception: Some findings and applications. In M. Heller \& W. Schiff (Eds.), The psychology of touch (pp. 189-210). Hillsdale, NJ: Erlbaum.

SHImizU, Y. (1986). Tactile display terminal for the visually handicapped. Displays, 7, 116-120.

Shimizu, Y., Saida, S., Wake, T., Nakamura, A., \& Ohzu, H. (1982). Optimum design of tactile display for a reading aid. In J. Raviv (Ed.), Uses of computers in aiding the disabled (pp. 383-391). Amsterdam: North-Holland.

Wake, T., Shimizu, Y., \& Wake, H. (1980). Perception of tactile three-dimensional information and visual aids for the blind. Japanese Journal of Ergonomics, 16, 27-36.

W ARREN, D. H. (1984). Blindness and early childhood development. New York: American Foundation for the Blind.

WEINSTEIN, S. (1968). Intensive and extensive aspects of tactile sensitivity as a function of body part, sex, and laterality. In D. Kenshalo (Ed.), The skin senses (pp. 195-222). Springfield, IL: Charles C Thomas.

(Manuscript received December 3, 1991; revision accepted for publication June 16,1992 .) 